\title{
1 Characterization of the utility of three nebulizers in investigating infectivity of
}

$5 \quad{ }^{a}$ Queensland University of Technology (QUT), Faculty of Science, School of Earth and Atmospheric

6 Sciences, Brisbane 4001, Australia

$7{ }^{\mathrm{b}}$ Queensland University of Technology (QUT), Faculty of Health, School of Biomedical Sciences, 8 Brisbane 4001, Australia

$9{ }^{\mathrm{c}}$ Queensland University of Technology (QUT), Faculty of Health, School of Biomedical Sciences, Centre for Immunology and Infection Control, Brisbane 4001, Australia

\#Address correspondence to Graham R. Johnson, g.johnson@qut.edu.au

Running Head: Utility of nebulizers in studying of airborne virus

\section{Abstract}

Laboratory-generated bioaerosols are widely used in aerobiology studies of viruses, however few comparisons of alternative nebulizers exist. We compared aerosol production and virus survival for a Collison nebulizer, vibrating mesh nebulizer (VMN), and hydraulic spray atomizer (HAS). We also measured the dry size distribution of the aerosols produced, calculated the droplet sizes before evaporation and the dry size distribution from normal saline solution. Dry count median diameters of $0.25,0.63$ and $0.76 \mu \mathrm{m}$ were found for normal saline from the Collison nebulizer, VMN and HSA, respectively. The volume median diameters were 2.91, 3.2 and $2.43 \mu \mathrm{m}$,

25 respectively. The effect of nebulization on the viability of two influenza A viruses (IAVs) $(\mathrm{H} 1 \mathrm{~N} 1, \mathrm{H} 3 \mathrm{~N} 2)$ and human rhinovirus (HRV)-16, was assessed by direct nebulization into an

27 SKC Biosampler. The HSA had least impact on surviving fractions (SFs) of H1N1 and H3N2 $28(89 \pm 5 \%, 94 \pm 3 \%)$, followed by the Collison nebulizer $(82 \pm 2 \%, 82 \pm 3 \%)$. The VMN yielded SFs 
29

30

31

32

of $78 \pm 2 \%$ and $76 \pm 2 \%$, respectively. Conversely, for HRV-16, the VMN produced higher SFs $(86 \pm 15 \%)$. Our findings indicate that although the VMN had the greatest impact on IAV survival, it produced higher aerosol concentrations within the airborne-size range making it more suitable where high aerosol mass production is required.

\section{Importance}

Viral respiratory tract infections cause millions of lost days of work and physician visits globally, accounting for significant morbidity and mortality. Respiratory droplet and droplet nuclei from infected hosts are the substantial potential carriers of such viruses within indoor environments. Laboratory-generated bioaerosols are applied in understanding the transmission and infection of viruses, simulating the physiological aspects of bioaerosol generation in a controlled environment. However, little comparative characterization exists for nebulizers used in infectious disease aerobiology, including Collison nebulizer, Vibrating mesh nebulizer, and hydraulic spray atomizer. This study characterized the physical features of aerosols generated by laboratory nebulizers, and their performance in producing aerosols at a size relevant to airborne transmission used in infectious disease aerobiology. We also determined the impact of nebulization mechanisms of these nebulizers on the viability of human respiratory viruses, including IAV H1N1, IAV H3N2 and HRV-16.

\section{Introduction}

Respiratory viruses are responsible for significant morbidity and mortality as well as millions of lost days of work and physician visits globally $(1,2)$. Evidence suggests that the airborne mode of transmission plays a significant role in the spread of respiratory viruses $(3,4)$. Respiratory droplets and droplet nuclei generated from the human host respiratory system are potential carriers of pathogens within indoor environments $(5,6)$. However, there is no consistent explanation that fully addresses the ability of these viruses to survive in an airborne state (7). It has been reported that a combination of environmental and biological factors can affect the efficiency of airborne transmission of viruses in indoor environments (8). In modelling airborne transmission, laboratory-generated pathogen-laden aerosols are broadly used to investigate the 
transmission, infection and toxicology of respiratory viruses (8-10). Techniques used to generate virus-laden aerosols in the laboratory enable greater control over aerosol characteristics, including their droplet concentration, size and efficacy for carrying viruses (11). Animal models have also been used to investigate the infection course and pathogenesis of inhaled microorganisms (12). Here, the route of exposure, aerosol size, and infectious dose can influence the infection development and pathogenic outcomes. In these models, the method of aerosolization is critical, as reduced virus viability due to mechanical preparation would influence study outcomes. Considering this critical factor, the field lacks a comprehensive study that fully characterizes the physical and biological properties of carrier aerosols generated by laboratory-use nebulizers, particularly for the simulation of respiratory virus-laden aerosols in a clinical environment.

The Collison nebulizer, as the gold standard, has dominated bioaerosol generation research since its invention in 1932 (13-15). It applies Bernoulli's theory, impaction of a liquid suspension against the interior of a glass to generate small size aerosols (16). The type of liquid suspension, its viscosity and surface tension, are the principal factors that influence the droplet size and concentration of aerosols generated by a Collison nebulizer (17). Within the literature reporting Collison nebulizer generated aerosols, studies utilize different nebulization solution viscosities, resulting in the multiple size distributions reported from Collison use. It has also been hypothesized that impaction, shear forces and recirculation of an infectious sample within the

77 Collison nebulizer may damage microorganisms, potentially decreasing pathogen viability or infectivity $(18,19)$. However, there is no available well-designed studies to test these effects on pathogen viability.

The vibrating mesh nebulizer (VMN), has been introduced more recently as a high performance treatment delivery system for patients with respiratory diseases $(20,21)$. VMNs employ electroformed plates that vibrate to generate aerosols (22). Two types of VMN, passive and active, have been commercially deployed. An example of a passive VMN is the Omron MicroAir NE-U22, which contains a perforated vibrating plate underlying the fluid reservoir with around 6000 tapered holes of $3 \mu \mathrm{m}$ diameter. Alternatively, the Aeroneb Pro nebulizer is an 86 active VMN, utilizing a micropump system which delivers fluid to a vibrating plate containing 87 up to 1000 dome-shaped apertures. In both systems, aerosols are generated by applying an 
alternating electric potential to a piezoelectic, triggering the mesh to move back and forth by a few micrometres to aerosolize liquids brought into contact with the mesh surface (17). An alternative to the Collison and VMN nebulization, is the hydraulic spray atomizer (HSA). The HSA concentrates the suspension into a stream by forcing it through a very small hole. There is a one-way valve in the nozzle that maintains air from flowing back into the pump and allows for suction within the pump so that liquid can be pulled up the tube. However, these latter two types of nebulizer VMN and HSA have rarely been applied in the infectious disease aerobiology research field. In this study, we hypothesized that a VMN or an HSA is superior to the commonly used Collison nebulizer, as they result in less mechanical stress on respiratory viruses and therefore enable a higher viable dose to be delivered for experimental purposes.

This study was therefore designed to determine the influence of nebulization methods of the 1-jet Collison nebulizer, VMN and HSA on the viability of human respiratory viruses Influenza A virus (IAV) H1N1, IAV H3N2 and Human rhinovirus-16 (HRV-16). We also characterized the size and weight of aerosols produced by these three nebulizers.

\section{Results}

$\underline{\text { Aerosol Output and Size Analysis }}$

Figure 1 shows the lognormal fit to ASD normalised with respect to the maximum sizing channel concentration of the dried aerosols generated by the Collison nebulizer, VMN and HSA loaded with $0.05 \mathrm{~g} \mathrm{~L}^{-1} \mathrm{NaCl}$ solution as measured with SMPS. Initial droplet size (dotted curves) of these aerosols before evaporation were calculated using Equation 1 and finally the ASDs were calculated for a solution composed of $9 \mathrm{~g} \mathrm{~L}^{-1} \mathrm{NaCl}$ (dashed curves). Table 1 summarizes the detailed properties of the aerosols produced. The Collison generated smaller aerosols compared to the other two nebulizers, with count median diameters (CMD) of $0.045 \mu \mathrm{m}$ and 0.25

$113 \mu \mathrm{m}$ for $0.05 \mathrm{~g} \mathrm{~L}^{-1}$ and $9 \mathrm{~g} \mathrm{~L}^{-1} \mathrm{NaCl}$ solutions, respectively. However, the corresponding volume 114 median diameters (VMD) of these two $\mathrm{NaCl}$ solutions were $0.50 \mu \mathrm{m}$ and $2.91 \mu \mathrm{m}$. VMN 115 generated larger aerosols than the Collison with a CMD of $0.11 \mu \mathrm{m}$ and $0.63 \mu \mathrm{m}$ for $0.05 \mathrm{~g} \mathrm{~L}^{-1}$ 116 and $9 \mathrm{~g} \mathrm{~L}^{-1} \mathrm{NaCl}$ solutions, and VMD of $0.56 \mu \mathrm{m}$ and $3.2 \mu \mathrm{m}$, respectively. HSA generated the 
117 largest aerosols with CMD of $0.13 \mu \mathrm{m}$ and $0.76 \mu \mathrm{m}$, although the VMD were $0.43 \mu \mathrm{m}$ and 2.43

$118 \mu \mathrm{m}$, for $0.05 \mathrm{~g} \mathrm{~L}^{-1}$ and $9 \mathrm{~g} \mathrm{~L}^{-1} \mathrm{NaCl}$ solutions, respectively. The geometric standard deviations

119 (GSDs) of the aerosols produced by the Collison, VMN and the HSA were 2.47, 2.09 and 1.86,

120 respectively, indicating that HSA generated a more uniform aerosol size compared to the other

121 two nebulizers.

122 Viral Surviving Fractions Post-Aerosolization

123

124

125

126

127

128

129

130

131

132

133

134

135

136

137

138

139

140

141

142

143

144

145

Comparison of SFs for IAVs H3N2 and H1N1 and HRV-16 for Collison, VMN and HSA were performed by nebulization of viral suspension directly into an operating SKC cup and results are presented in Figure 2. The average SFs of IAV H1N1 for the Collison, VMN and HSA were $0.82 \pm 0.02,0.78 \pm 0.02$ and $0.89 \pm 0.05$, respectively, while the average SFs for IAV H3N2 were $0.82 \pm 0.03,0.76 \pm 0.02$ and $0.94 \pm 0.03$. The corresponding average SFs of HRV-16 after running the Collison, VMN and HSA were $0.83 \pm 0.08,0.86 \pm 0.15$ and $0.85 \pm 0.06$, showing that these nebulizers had little effect on HRV-16 survival compared to that of survival of IAV strains. Although HSA is slightly better for IAVs, One-way ANOVA demonstrated no statistic differences in SFs of the tested viruses between three mentioned nebulizers.

We also tested the shear and impact forces delivered by the high-velocity air streams of the 1- jet Collison nebulizer on the viability of viruses suspended during 30 min run times (Figure 3). There was a gradual decrease in SFs for all three viruses over $30 \mathrm{~min}$. SFs of IAVs H1N1 and $\mathrm{H} 3 \mathrm{~N} 2$ declined from $0.82 \pm 0.02$ at $5 \mathrm{~min}$ to $0.67 \pm 0.03$ at $30 \mathrm{~min}$, and $0.82 \pm 0.03$ at $5 \mathrm{~min}$ to $0.68 \pm 0.02$ at $30 \mathrm{~min}$, respectively, these differences between 5 and $30 \mathrm{~min}$ operating times were statistically significant $(P=0.003$ and $P=0.012$, respectively), suggesting that the Collison may not be an appropriate option for studies that require longer nebulizer operating time or high concentration of viable virus in aerosols. However, the SF of HRV-16 decreased less, from $0.83 \pm 0.08$ at $5 \mathrm{~min}$ to $0.73 \pm 0.05$ at $30 \mathrm{~min}$, which was not significantly different, suggesting that HRV is less susceptibility to mechanical stress compared to IAVs. 


\section{Discussion}

The techniques used to generate laboratory bioaerosols simulate the physiological aspects of bioaerosol generation in a controlled environment. These techniques enable greater understanding of the airborne mode in the transmission of respiratory viruses. However, the mechanism of aerosol generation affects the characteristics of the aerosols produced, including their physical and chemical properties, and influences their properties compared to bioaerosols generated from natural sources. We conducted this study to characterize the features of aerosols generated by three commonly used nebulizers, including the 1-jet Collison nebulizer, VMN and HSA. We also tested nebulizer impacts on the stability and infectivity of IAVs H1N1, H3N2 and HRV-16 viruses immediately post-nebulization. Our detailed characterization found that the Collison produced aerosols with CMD of $0.25 \mu \mathrm{m}$ when derived from a solution of $9 \mathrm{~g} \mathrm{~L}^{-1} \mathrm{NaCl}$ concentration. This salt concentration is consistent with the salt concentration of standard cell culture media as the potential suspension for viral particles. The size diameters of the HRV-16 (23) and IAVs (24) are 30 and 80-120 nm, respectively, therefore, any aerosols smaller than this would not be able to carry viral particles, although could carry non-infectious viral fragments. Previous studies reported that a Collison nebulizer produces high concentrations of aerosols which were monodisperse with a MMD between 1-2 $\mu \mathrm{m}$ (25). Based on the particles size distributions generated from a Collison nebulizer, May et al. stated that only 1 percent of the mass of producing aerosols is larger than $5 \mu \mathrm{m}(26,27)$. A study conducted by Ibrahim et al. reported that the CMD of the aerosols produced by the Collison nebulizer is between 33 and 38 $\mathrm{nm}$, which is not large enough to carry an Influenza virus particle (> $80 \mathrm{~nm}$ ) (28). However, fluid physiochemical properties such as viscosity, surface tension (29) and the type and concentration of ions (30) can highly influence the nebulizer aerosol performance. Our results indicated that the physical aspects of aerosols, including CMD and VMD depend on the concentration of ions in

172 solution used. VMN produced aerosols in an airborne size range with the CMD of $0.63 \mu \mathrm{m}$ 173 derived from a solution of $9 \mathrm{~g} \mathrm{~L}^{-1} \mathrm{NaCl}$, which is larger than most viruses, suggesting that VMN 174 is suited to investigations of airborne virus-laden aerosols in terms of aerosol's physical size. 175 HSA atomized aerosols were larger than those generated by the two other nebulizers, but were 
176 still within the airborne range size, with a CMD of $0.76 \mu \mathrm{m}$ for $9 \mathrm{~g} \mathrm{~L}^{-1} \mathrm{NaCl}$ solution. However,

177 HSA nebulization produced a lower concentration of aerosols in the same running time, followed

178 by 1 -jet Collison nebulizer. This property could disadvantage studies that require a higher

179 concentration of aerosols or viral doses. In terms of SF reductions of IAV H1N1and H3N2, the

180 decline in viral viability with HSA was minimal, with an average of $0.89 \pm 0.05$ and $0.94 \pm 0.03$,

181 respectively, followed by the Collison and VMN. However, VMN produced the highest SFs of

182 HRV-16 (0.86 \pm 0.15$)$, which is a non-enveloped virus, and may suggest that non-enveloped

183 viruses survive nebulization better than enveloped viruses, such as IAV. Our findings showed

184 that the SFs of all three viruses were reduced in samples collected from virus suspensions in the

185 glass of the 1-jet Collison nebulizer after 30 minutes running time and that the loss was highest

186 for enveloped IAVs compared to the non-enveloped HRV-16. Consistent with our findings, it

187 was previously reported that the method of the aerosol production in the Collison jar could

188 damage intact pathogens, effecting the pathogen dose required to identify an infection signal

189 (31). Kim et al. reported a loss of $15 \%$ in titre of an enveloped coronavirus (80-160 nm) during

190 Collison nebulization over a period of 30 minutes (32). Conversely, Hermann et al. reported no

191 loss in the viabilities of enveloped porcine reproductive and respiratory syndrome virus (40-80

$192 \mathrm{~nm}$ ) through $55 \mathrm{~min}$ of nebulization using a 24-jet Collison (33). The inconsistency between

193 reported results of viable fractions post-aerosolization is likely due to large variations in methods

194 used for measuring SFs and differences in the size of viruses tested. Experimental protocols

195 which significantly impact results include aerosol sampling and measuring, and the degree of

196 control over temperature and RH. In fact, the Collison nebulizer inherently needs a high volume

197 of virus suspension $(10 \mathrm{~mL})$ compared to other nebulizers, which can dilute the titre of initial

198 virus stocks and reduce the aerosolized doses provided. The Collison also generates foam from

199 suspensions with high organic content which could be a barrier for proper aerosolization of virus

200 laden droplets (Supplementary Figure 1). Finally, we summarized the advantages and

201 disadvantages of investigated nebulizers in Table 2.

202

203

204

205

206
This study was conducted to investigate the characteristics of aerosols generated by commonly used nebulizers using SMPS instrumentation. CMD and VMD of aerosols generated by the Collison placed at $0.25 \mu \mathrm{m}$ and $2.91 \mu \mathrm{m}$, while VMN produced aerosols with CMD and VMD of $0.63 \mu \mathrm{m}$ and $3.2 \mu \mathrm{m}$. HSA generated larger aerosols with CMD and VMD of $0.76 \mu \mathrm{m}$ and $2.43 \mu \mathrm{m}$. VMN generated higher concentrations of aerosols over the same running time 
compared to the other two nebulizers. SFs of IAV H1N1, IAV H3N2 and HRV-16 decreased post-nebulization, but this was dependent on virus type (enveloped or non-enveloped) and nebulization mechanisms. HSA elicited the least mechanical stress on the investigated IAV strains; however, the gravitational loss of aerosols was higher due to the generation of large size droplets. Our results indicated that VMN is the best nebulizer for infectious disease aerobiology research due to its production of aerosols in a usable size range (200nm-5000nm), higher aerosol mass injection rate $\left(2 \mathrm{~g} \mathrm{~min}^{-1}\right)$ which allows short duration injection and good aging time resolution. The VMN does not inject air, therefore it is suitable for studies that require modulation of RH and temperature control within enclosed chambers.

\section{Materials and Methods}

Aerosol Size Distribution Measurement: The droplet size distribution produced by each of the nebulizers was back calculated after measuring the dry salt aerosol size distribution produced from a saline solution of known concentration. Aerosols (without addition of viruses) were generated by briefly nebulizing a suspension of $0.05 \mathrm{~g} \mathrm{~L}^{-1} \mathrm{NaCl}$ into a $400 \mathrm{~L}$ rotating stainless steel drum developed based on the TARDIS-Rotator (34). The drum was first flushed with HEPA-filtered air and the relative humidity (RH) was adjusted to 30\%, well below the efflorescence $\mathrm{RH}$ of $\mathrm{NaCl}$ and the nebulization time limited to ensure generated aerosols dried rapidly and were sampled by the aerosol measurement instrumentation in the dry state. The dry aerosol size distribution (ASD) of aerosols produced by the 1-jet Collison nebulizer, VMN, and HSA were measured using a scanning mobility particle sizer (SMPS 3034, TSI Inc., Shoreview, MN, USA). A dilute sample solution $\left(0.05 \mathrm{~g} \mathrm{~L}^{-1}\right)$ was used for measurements to ensure that the dry aerosols were within the size range of the SMPS which is between 9 to $1000 \mathrm{~nm}$, depending on operating conditions. We then calculated the initial droplet sizes. Subsequently we were able to calculate the dry sizes of aerosols expected from a solution with salt concentration of $9 \mathrm{~g} \mathrm{~L}^{-1}$, similar to a physiological saline solution, using Equation 1 and this size distribution was validated through direct measurement of the portion of that dry size distribution accessible to the SMPS. 
$D_{\text {dry }}=D_{\text {wet }} \times\left(\frac{C_{\text {Solution }}}{\rho_{\text {solution }}}\right)^{1 / 3}$ where:

$D_{\text {dry }}=$ Final dry diameter of aerosol.

$D_{\text {wet }}=$ Initial diameter of the solution dropet .

$C_{\text {solution }}=$ Concentration of solution $\left(\mathrm{kg} \mathrm{m}^{-3}\right)$.

$\rho_{\text {solution }}=$ Density of solution $\left(\mathrm{kg} \mathrm{m}^{-3}\right)$.

Virus Propagation: HRV-16 was grown in Ohio HeLa cells in VP-SFM medium (Life Technologies, USA) and propagated according to standard protocols (35) (Supplementary Text I). IAV H1N1 and H3N2 were propagated in the allantoic fluid of 10-day old embryonated chicken eggs (36) (Supplementary Text II).

Virus Suspensions: IAV H1N1, IAV H3N2 and HRV-16 virus batches were added to a suspension composed of phosphate buffer saline (PBS) and fetal bovine serum (FBS). The salt and total protein contents were 10 and $8 \mathrm{~g} \mathrm{~L}^{-1}$, respectively, which is approximately comparable to the ratio of salts and proteins found in human respiratory fluid (37). This solution provided an environment with neutral $\mathrm{pH}$ that allowed the viruses to remain viable, while attempting to physiologically model the actual composition of human respiratory fluid.

Experimental Setup for Measuring Viruses Viabilities: Figure 4 illustrates the experimental set up for testing the mechanical stress of Collison nebulizer (upper panel), VMN and HSA (lower panel) on the viability of viruses. HEPA- filtered compressed air with a flow rate of $12 \mathrm{~L} \mathrm{~min}^{-1}$ and pressure of 26 to $30 \mathrm{lb} \mathrm{in}^{-2}$ was blown into the glass of the 1-jet Collison nebulizer to produce carrier aerosols. Virus-laden aerosols were collected into an SKC Biosampler directly after nebulization in $5 \mathrm{~mL}$ PBS. The photographs of experimental set ups also are shown in

256 Supplementary Figure 2. The SKC Biosampler (\#225-9593, SKC) is an advanced impinger257 type air sampler that collects airborne aerosols using a whirling flow of liquid (PBS) and pump 
$0.630 \mathrm{~mm}$ tangential sonic nozzles (38). A HEPA filter was connected to provide required excess air for sampling. Our VMN (Supplementary Figure 3) was assembled inside a biosafety cabinet. It consisted of the nebulizer electroform plate, $3 \mathrm{~mL}$ reservoir and electrical wires, which were connected to a high frequency circuit inside of the biosafety cabinet. The virus suspension was injected into the nebulizer reservoir via a Luer lock syringe. As the final step, the virus suspension was aerosolized directly into an SKC cup and simultaneously collected into $5 \mathrm{~mL}$ PBS by running the SKC pump. The same experimental set up was applied for testing HSA and the virus suspension was nebulized using a $10 \mathrm{~mL}$ Luer lock syringe.

$T_{C I D_{50}}$ to Determine HRV-16 Titer: The change in titer of HRV-16 before and after nebulization was quantified using a standard TCID at which $50 \%$ of HeLa cells cultured in monolayer demonstrated a cytopathic effect $\left(\mathrm{CPE} ; \mathrm{TCID}_{50}\right)$ (39). Cells were exposed to replicate 10-fold serial dilutions of the fluid collected for HRV-16 in the BioSampler for four days at $34{ }^{\circ} \mathrm{C}$. CPE was then identified for each well in the TCID $_{50}$ assay using $0.01 \%$ crystal violet solution mixed with $60 \%$ ethanol and $40 \%$ methanol.

Plaque Assay to Determine IAV H1N1 and IAV H3N2 Titers : IAV H1N1 and H3N2 infectivity titers were measured by plaque formation on confluent monolayers of Madin-Darby canine kidney (MDCK) cells cultured in RF10 medium (40). Once cells in 6 well plates were confluent, media was replaced with $135 \mu \mathrm{L}$ RPMI containing 10-fold serial dilutions of recovered sample. Plates were incubated $\left(37{ }^{\circ} \mathrm{C}, 5 \% \mathrm{CO}_{2}\right)$ for $45 \mathrm{~min}$, and each $15 \mathrm{~min}$ gently rocked to distribute the virus evenly and prevent drying of the cell monolayer. Cells were then overlayed with $3 \mathrm{~mL}$ per well of L15 media mixed with $0.1 \%$ trypsin and $1.8 \%(\mathrm{w} / \mathrm{v})$ agarose. Once set, plates were incubated $\left(37{ }^{\circ} \mathrm{C}, 5 \% \mathrm{CO}_{2}\right)$ for 3 days. Plaque formation was visualized by staining the monolayer with $0.01 \%$ crystal violet solution, and number of plaques were counted as a measure of virus infectivity. Experimentation was conducted according to health risk assessment, QUT biosafety committee approval (Approval number:1800000969).

Surviving Fraction and Statistical Analysis: Surviving Fractions (SFs) of IAVs (H1N1/H3N2) and HRV-16 were calculated using Equation 2. RNA was used as a natural tracer of dilution based on the expectation that RNA was present in the same ratio to total virus in the nebulizer before aerosolization and after sample collection (39). Viral RNA was extracted from nebulizers and SKC BioSampler samples by QIAamp Viral RNA Mini Kit (Qiagen, USA) and its 
289

290

291

292

293

294

295

\section{Equation 2}

$S F=D \times\left(\frac{L V C_{A}}{O L V C_{N}}\right)$, where:

$\mathrm{D}=\left(\frac{R N A_{N}}{R N A_{A}}\right)$ is the dilution factor and:

$L V C_{A}=$ live virus concentration (PFU or TCID50) in the extracted aerosol sample.

$O L V C_{N}=$ original live virus concentration (PFU or TCID50) in the nebulizer.

$R N A_{A}=$ total RNA mass concentration in the extracted aerosol sample.

$R N A_{N}=$ original total $R N A$ mass concentration in the nebulizer.

297 The concentrations of extracted RNA (ng mL ${ }^{-1}$ ), PFU mL ${ }^{-1}$ (IAV H1N1 and IAV H3N2) and $298 \mathrm{TCID}_{50} \mathrm{~mL}^{-1}(\mathrm{HRV}-16)$ for each experiment operated by 1-jet Collison, VMN and HSA are 299 presented in (Supplementary Table 1). Supplementary Table 2 also shows the concentrations 300 of extracted RNA (ng mL ${ }^{-1}$ ), PFU mL ${ }^{-1}$ (IAV H1N1 and H3N2) and TCID $50 \mathrm{~mL}^{-1}$ (HRV-16) for 301 each experiment operated by 1-jet Collison after 10, 20 and 30 minutes nebulization. All 302 experiments were conducted in biological triplicate. A One-way analysis of variance (ANOVA) 303 was performed to compare SFs of viruses between nebulizers. P value less than 0.05 was 304 considered statistically significant.

\section{Supplementary Data}

307 Supplemental material for this article may be found at...

\section{Acknowledgements.}



The research described here was sponsored by Australian Research Council (grant number DP170102733). We thank Dr. Kirsty R short for allowing us to propagate influenza A viruses in her laboratory.

\section{References}

1. Goka EA, Vallely PJ, Mutton KJ, Klapper PE. 2015. Single, dual and multiple respiratory virus infections and risk of hospitalization and mortality. Epidemiology and Infection 143:37-47.

2. Giraud-Gatineau A, Colson P, Jimeno M-T, Zandotti C, Ninove L, Boschi C, Lagier J-C, La Scola B, Chaudet $H$, Raoult D. 2020. Comparison of mortality associated with respiratory viral infections between December 2019 and March 2020 with that of the previous year in Southeastern France. International Journal of Infectious Diseases 96:154-156.

3. Ijaz MK, Zargar B, Wright KE, Rubino JR, Sattar SAJAJoIC. 2016. Generic aspects of the airborne spread of human pathogens indoors and emerging air decontamination technologies. 44:S109S120.

4. Huang S-H, Kuo Y-M, Lin C-W, Ke W-R, Chen C-CJA, Research AQ. 2019. Experimental Characterization of Aerosol Suspension in a Rotating Drum. 19:688-697.

5. Richard M, Fouchier RAJFmr. 2015. Influenza A virus transmission via respiratory aerosols or droplets as it relates to pandemic potential. 40:68-85.

6. Herfst S, Böhringer M, Karo B, Lawrence P, Lewis NS, Mina MJ, Russell CJ, Steel J, de Swart RL, Menge CJCoiv. 2017. Drivers of airborne human-to-human pathogen transmission. 22:22-29.

7. Vejerano EP, Marr LC. 2018. Physico-chemical characteristics of evaporating respiratory fluid droplets. Journal of The Royal Society Interface 15:20170939.

8. Kormuth KA, Lin K, Prussin AJ, Vejerano EP, Tiwari AJ, Cox SS, Myerburg MM, Lakdawala SS, Marr LC. 2018. Influenza virus infectivity is retained in aerosols and droplets independent of relative humidity. The Journal of infectious diseases 218:739-747.

9. Thomas R, Davies C, Nunez A, Hibbs S, Flick-Smith H, Eastaugh L, Smither S, Gates A, Oyston P, Atkins TJJomm. 2010. Influence of particle size on the pathology and efficacy of vaccination in a murine model of inhalational anthrax. 59:1415-1427.

10. Niazi S, Groth R, Spann K, Johnson GR. 2020. The role of respiratory droplet physicochemistry in limiting and promoting the airborne transmission of human coronaviruses: A critical review. Environmental Pollution doi:https://doi.org/10.1016/j.envpol.2020.115767:115767.

11. Bowling JD, O'Malley KJ, Klimstra WB, Hartman AL, Reed DS. 2019. A Vibrating Mesh Nebulizer as an Alternative to the Collison Three-Jet Nebulizer for Infectious Disease Aerobiology. Applied and Environmental Microbiology 85:e00747-19.

12. Cheng YS, Irshad H, Kuehl P, Holmes TD, Sherwood R, Hobbs CH. 2008. Lung Deposition of Droplet Aerosols in Monkeys. Inhalation Toxicology 20:1029-1036.

13. Hermann J, Hoff S, Muñoz-Zanzi C, Yoon K-J, Roof M, Burkhardt A, Zimmerman JJVr. 2007. Effect of temperature and relative humidity on the stability of infectious porcine reproductive and respiratory syndrome virus in aerosols. 38:81-93. 
14. Kormuth KA, Lin K, Qian Z, Myerburg MM, Marr LC, Lakdawala SSJm. 2019. Environmental Persistence of Influenza Viruses Is Dependent upon Virus Type and Host Origin. 4:e00552-19.

15. Chan KH, Peiris JS, Lam SY, Poon LL, Yuen KY, Seto WH. 2011. The Effects of Temperature and Relative Humidity on the Viability of the SARS Coronavirus. Adv Virol 2011:734690.

16. May KR. 1973. The collison nebulizer: Description, performance and application. Journal of Aerosol Science 4:235-243.

17. Najlah M, Parveen I, Alhnan MA, Ahmed W, Faheem A, Phoenix DA, Taylor KMG, Elhissi A. 2014. The effects of suspension particle size on the performance of air-jet, ultrasonic and vibratingmesh nebulisers. International Journal of Pharmaceutics 461:234-241.

18. Fennelly KP, Tribby MD, Wu CY, Heil GL, Radonovich L, Loeb JC, Lednicky JA. 2015. Collection and measurement of aerosols of viable influenza virus in liquid media in an Andersen cascade impactor. Virus Adapt Treat 7:1-9.

19. Brown J, Tang J, Pankhurst L, Klein N, Gant V, Lai K, McCauley J, Breuer JJJoHI. 2015. Influenza virus survival in aerosols and estimates of viable virus loss resulting from aerosolization and airsampling. 91:278-281.

20. Dhand RJRc. 2002. Nebulizers that use a vibrating mesh or plate with multiple apertures to generate aerosol. 47:1406-16; discussion 1416-8.

21. Astudillo A, Leung SSY, Kutter E, Morales S, Chan H-KJEJoP, Biopharmaceutics. 2018. Nebulization effects on structural stability of bacteriophage PEV 44. 125:124-130.

22. Ghazanfari T, Elhissi AM, Ding Z, Taylor KMJljop. 2007. The influence of fluid physicochemical properties on vibrating-mesh nebulization. 339:103-111.

23. Palmenberg AC, Gern JE. 2015. Classification and evolution of human rhinoviruses. Methods Mol Biol 1221:1-10.

24. Rossman JS, Lamb RA. 2011. Influenza virus assembly and budding. Virology 411:229-36.

25. Swearengen JR. 2012. Biodefense research methodology and animal models. CRC Press.

26. May K. 1973. The Collison nebulizer: description, performance and application. Journal of Aerosol Science 4:235-243.

27. Lindsley WG, Blachere FM, Thewlis RE, Vishnu A, Davis KA, Cao G, Palmer JE, Clark KE, Fisher MA, Khakoo R. 2010. Measurements of airborne influenza virus in aerosol particles from human coughs. PloS one 5:e15100.

28. Ibrahim E, Harnish D, Kinney K, Heimbuch B, Wander JJB, Equipment B. 2015. An experimental investigation of the performance of a Collison nebulizer generating H1N1 influenza aerosols. 29:1142-1148.

29. Ghazanfari T, Elhissi AMA, Ding Z, Taylor KMG. 2007. The influence of fluid physicochemical properties on vibrating-mesh nebulization. International Journal of Pharmaceutics 339:103-111.

30. Najlah M, Vali A, Taylor M, Arafat BT, Ahmed W, Phoenix DA, Taylor KMG, Elhissi A. 2013. A study of the effects of sodium halides on the performance of air-jet and vibrating-mesh nebulizers. International Journal of Pharmaceutics 456:520-527.

31. Thomas RJ, Webber D, Hopkins R, Frost A, Laws T, Jayasekera PN, Atkins T. 2011. The Cell Membrane as a Major Site of Damage during Aerosolization of \&lt;em\&gt; Escherichia coli\&lt;/em\&gt. Applied and Environmental Microbiology 77:920.

32. Kim SW, Ramakrishnan MA, Raynor PC, Goyal SM. 2007. Effects of humidity and other factors on the generation and sampling of a coronavirus aerosol. Aerobiologia 23:239-248.

33. Hermann JR, Hoff SJ, Yoon KJ, Burkhardt AC, Evans RB, Zimmerman JJ. 2006. Optimization of a Sampling System for Recovery and Detection of Airborne Porcine Reproductive and Respiratory Syndrome Virus and Swine Influenza Virus. Applied and Environmental Microbiology 72:4811. 
34. Johnson GR, Knibbs LD, Kidd TJ, Wainwright CE, Wood ME, Ramsay KA, Bell SC, Morawska L. 2016. A Novel Method and Its Application to Measuring Pathogen Decay in Bioaerosols from Patients with Respiratory Disease. PLoS One 11:e0158763.

35. Bartlett NW, Walton RP, Edwards MR, Aniscenko J, Caramori G, Zhu J, Glanville N, Choy KJ, Jourdan P, Burnet J. 2008. Mouse models of rhinovirus-induced disease and exacerbation of allergic airway inflammation. Nature medicine 14:199.

36. Short KR, Diavatopoulos DA, Reading PC, Brown LE, Rogers KL, Strugnell RA, Wijburg OL. 2011. Using bioluminescent imaging to investigate synergism between Streptococcus pneumoniae and influenza A virus in infant mice. Journal of visualized experiments: JoVE.

37. Potter JL, Matthews LW, Lemm J, Spector S. 1963. Human pulmonary secretions in health and disease. Ann N Y Acad Sci 106:692-7.

38. willeke K, Lin X, Grinshpun SA. 1998. Improved Aerosol Collection by Combined Impaction and Centrifugal Motion. Aerosol Science and Technology 28:439-456.

39. Niazi S, Groth R, Cravigan L, He C, Tang JW, Spann K, Johnson GR. 2021. Susceptibility of an Airborne Common Cold Virus to Relative Humidity. Environmental Science \& Technology 55:499508.

40. Blachere FM, Cao G, Lindsley WG, Noti JD, Beezhold DH. 2011. Enhanced detection of infectious airborne influenza virus. Journal of Virological Methods 176:120-124.

\section{Legends}

Figure 1. Dried aerosols size distributions for aerosols generated by (a) Collision, (b) VMN and (c) HSA loaded with $0.05 \mathrm{~g} \mathrm{~L}^{-1} \mathrm{NaCl}$ (solid lines), their initial droplet sizes (dotted curves) and for a solution of $9 \mathrm{~g} \mathrm{~L}^{-1} \mathrm{NaCl}$ (dashed curves). The shading indicates the usable size (the size can carry respiratory viruses and is in the airborne size range), suitable for studying infectious diseases in the aerobiology research field.

Figure 2. Surviving fraction (calculated based on equation 2) of IAV H1N1, IAV H3N2 and HRV-16 immediately post-nebulization. Experiments were conducted in triplicate.

Figure 3. IAV H1N1, IAV H3N2 and HRV-16 SF declines following 30 min of 1-jet Collison nebulization. The $5 \mathrm{~min}$ SFs are taken from figure 3. The solid dash and dot lines present the statistical differences of SFs for H1N1 and H3N2 between 5 and 30 min. 
431 Figure 4. Experimental set up for measuring the effects of nebulization on the viability of 432 respiratory viruses (upper panel: Collison nebulizer and lower panel: VMN and HSA).

433 Table 1. The properties of dry and wet aerosols generated by Collison nebulizer, VMN and HSA 434 derived from two $\mathrm{NaCl}$ solutions.

\begin{tabular}{ccccc}
\hline Nebulizers and NaCl solutions & $\mathrm{CMD}(\mu \mathrm{m})$ & $\mathrm{VMD}(\mu \mathrm{m})$ & $\mathrm{GSD}$ & $\mathrm{RH}(\%)$ \\
Collison (0.05 $\mathrm{g} \mathrm{L}^{-1} \mathrm{NaCl}$ solution) & 0.045 & 0.50 & 2.47 & $30 \%$ \\
VMN (0.05 $\mathrm{g} \mathrm{L}^{-1} \mathrm{NaCl}$ solution) & 0.11 & 0.56 & 2.09 & $30 \%$ \\
$\mathrm{HSA}\left(0.05 \mathrm{~g} \mathrm{~L}^{-1} \mathrm{NaCl}\right.$ solution) & 0.13 & 0.43 & 1.86 & $30 \%$ \\
Collison $\left(9 \mathrm{~g} \mathrm{~L}^{-1} \mathrm{NaCl}\right.$ solution) & 0.25 & 2.91 & 2.47 & $30 \%$ \\
VMN $\left(9 \mathrm{~g} \mathrm{~L}^{-1} \mathrm{NaCl}\right.$ solution) & 0.63 & 3.20 & 2.09 & $30 \%$ \\
HSA (9 $\mathrm{g} \mathrm{L}^{-1} \mathrm{NaCl}$ solution) & 0.76 & 2.43 & 1.86 & $30 \%$ \\
Collison (initial droplets) & 1.56 & 23.10 & 2.47 & $100 \%$ \\
VMN (initial droplet) & 3.91 & 19.90 & 2.09 & $100 \%$ \\
HSA (initial droplet) & 4.73 & 15.1 & 1.86 & $100 \%$ \\
\hline
\end{tabular}


435 Table 2. advantages and disadvantages of nebulizers for studies in aerobiology field.

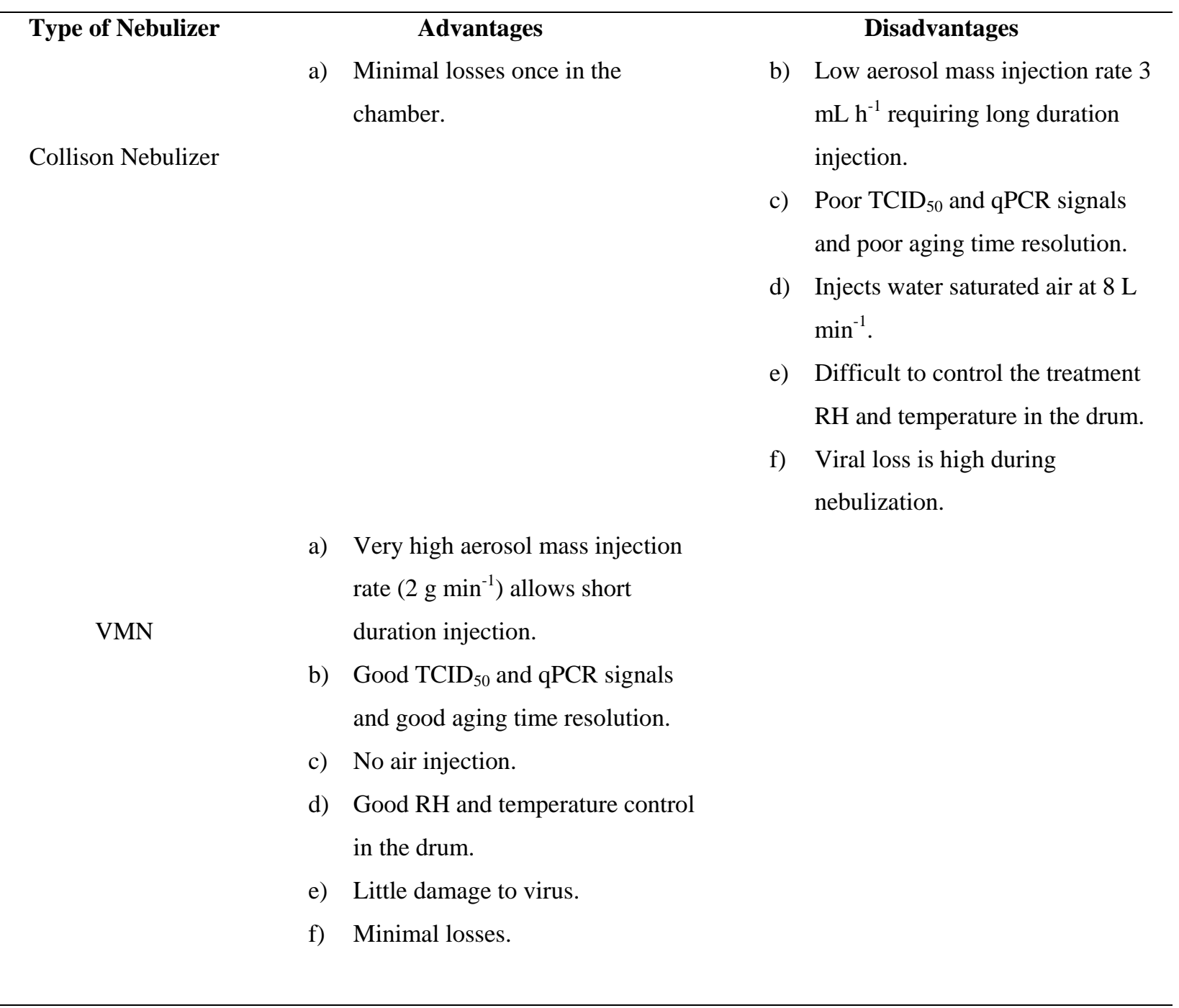



available under aCC-BY-NC-ND 4.0 International license.

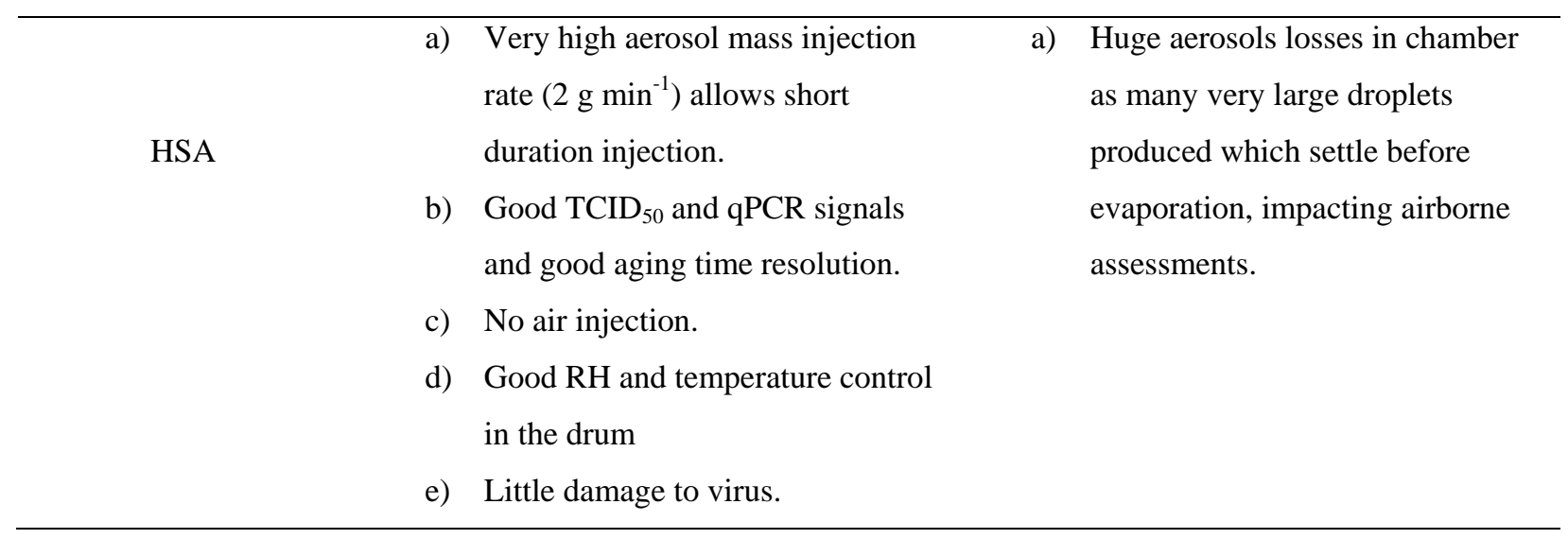



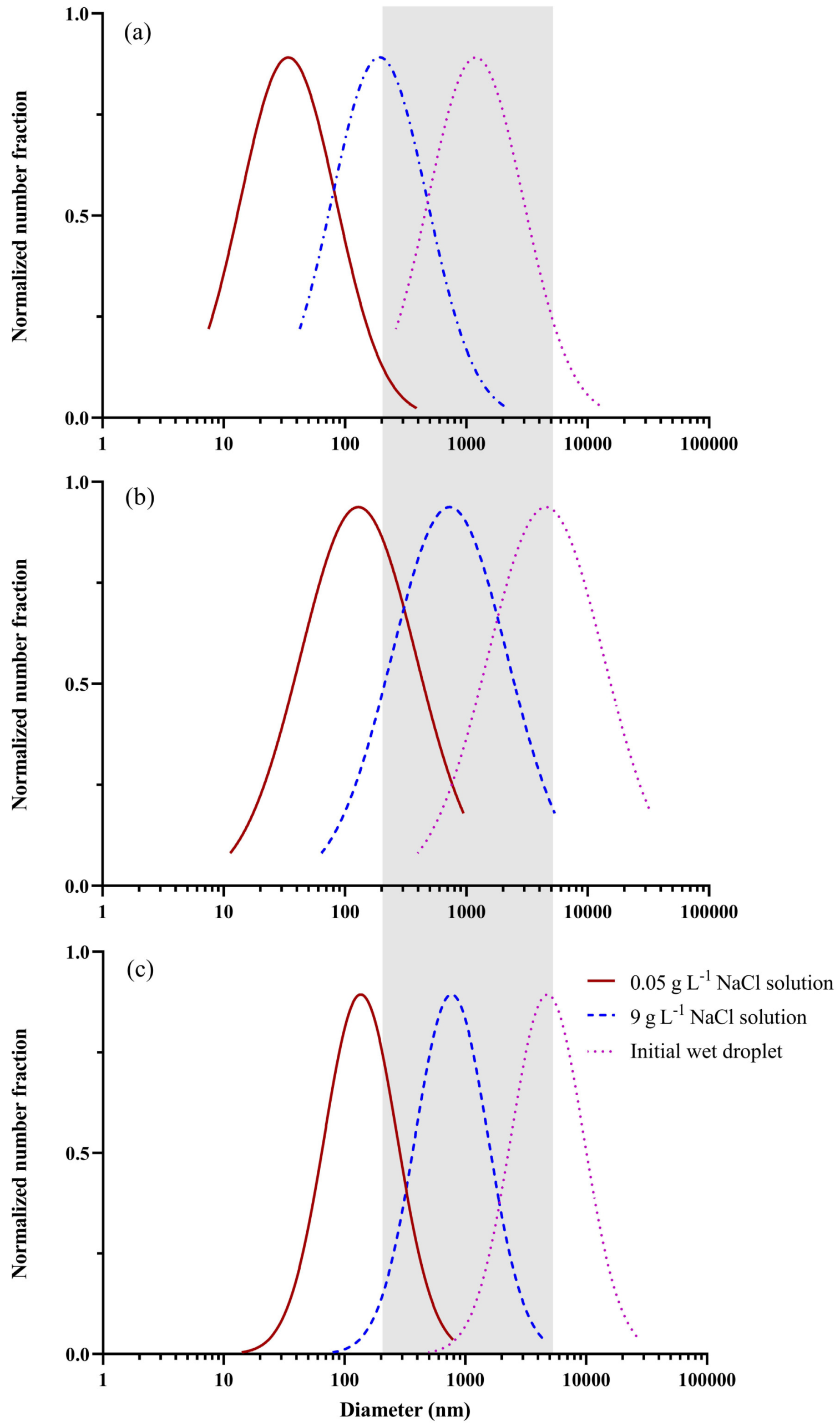


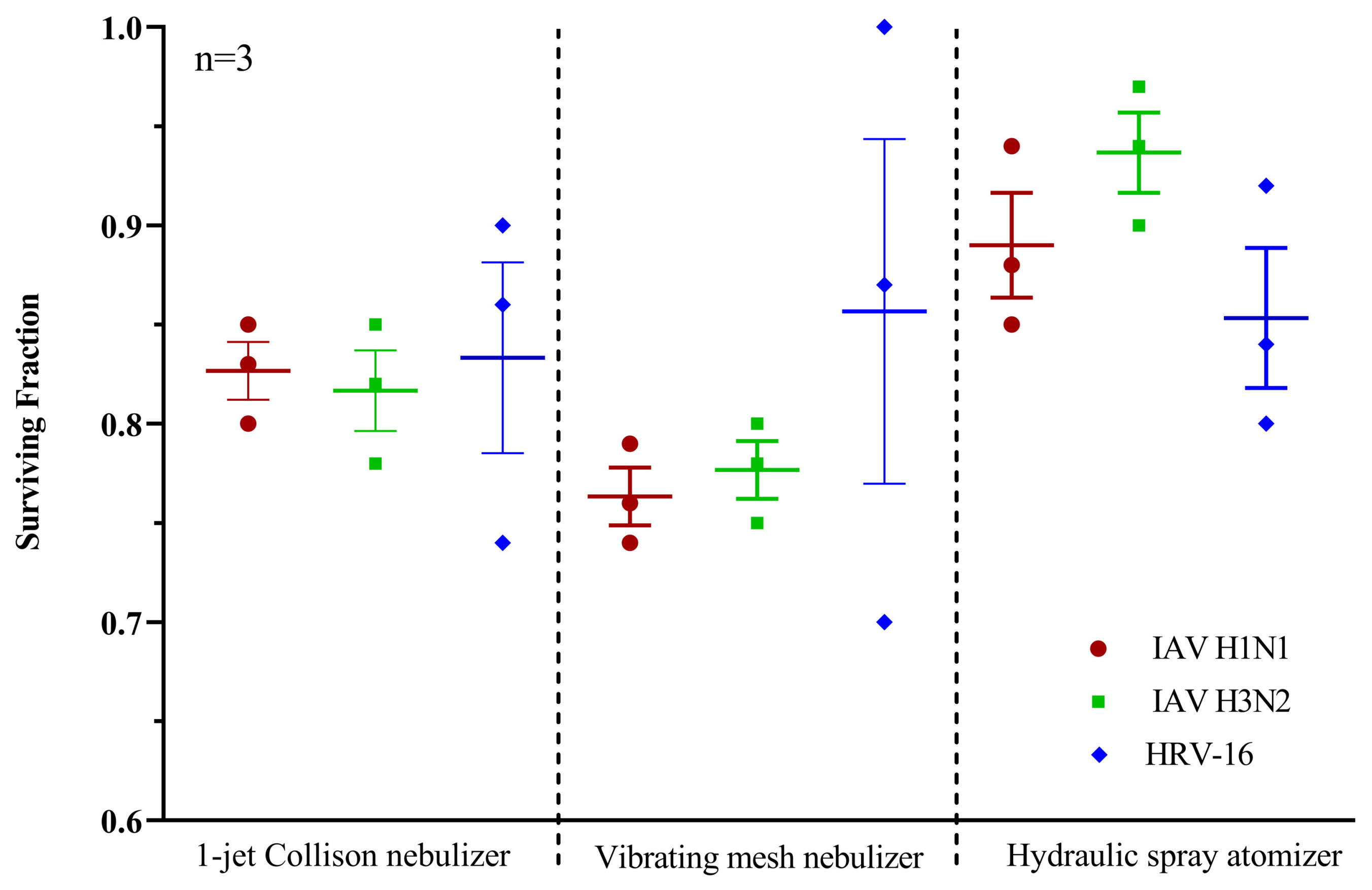




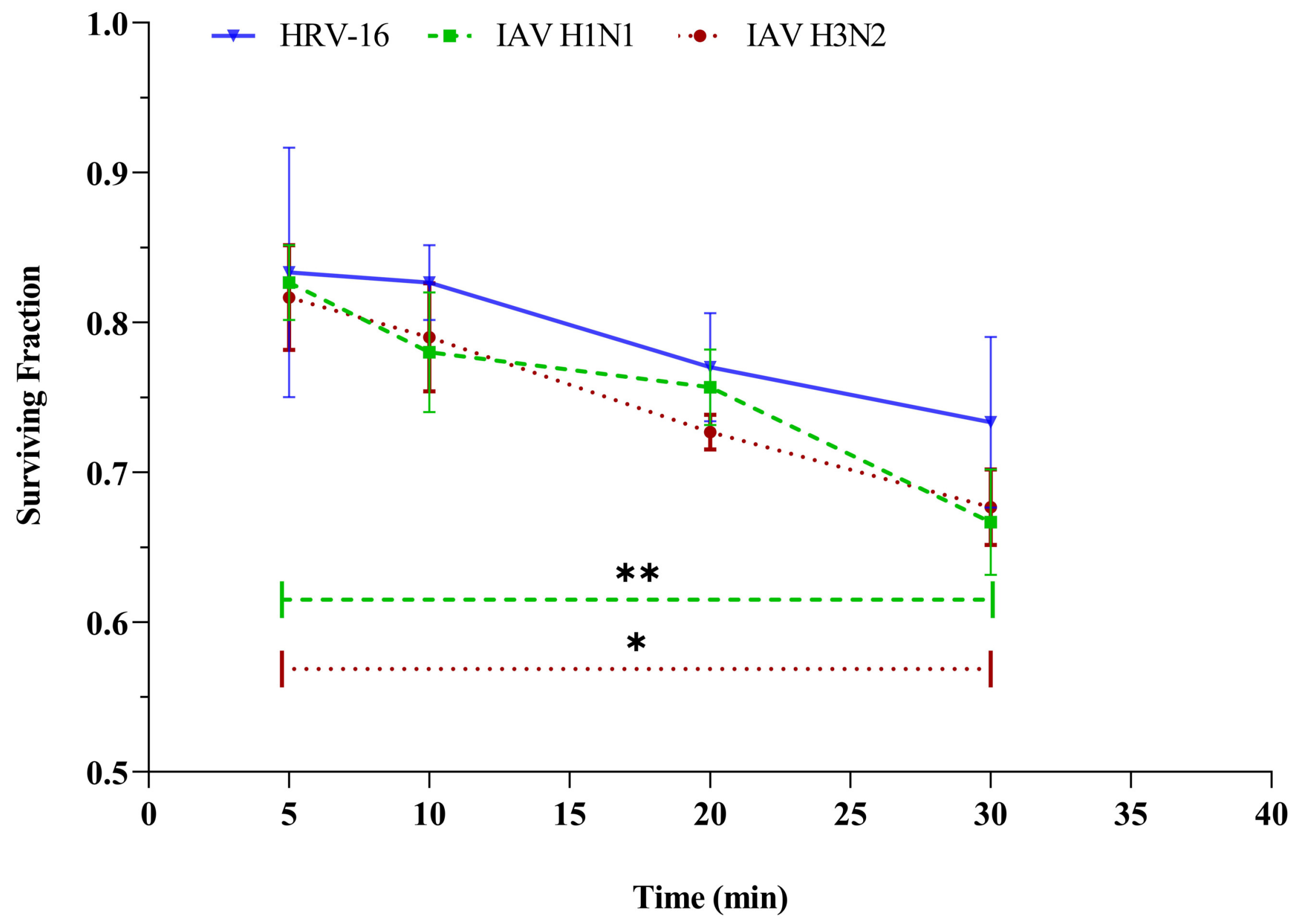


bioRxiv preprint doi: https://doi.org/10.1101/2021.03.11.435057; this version posted March 12, 2021. The copyright holder for this preprint (which was not certified by peer review) is the author/funder, who has granted bioRxiv a license to display the preprint in perpetuity. It is made available under aCC-BY-NC-ND 4.0 International license.

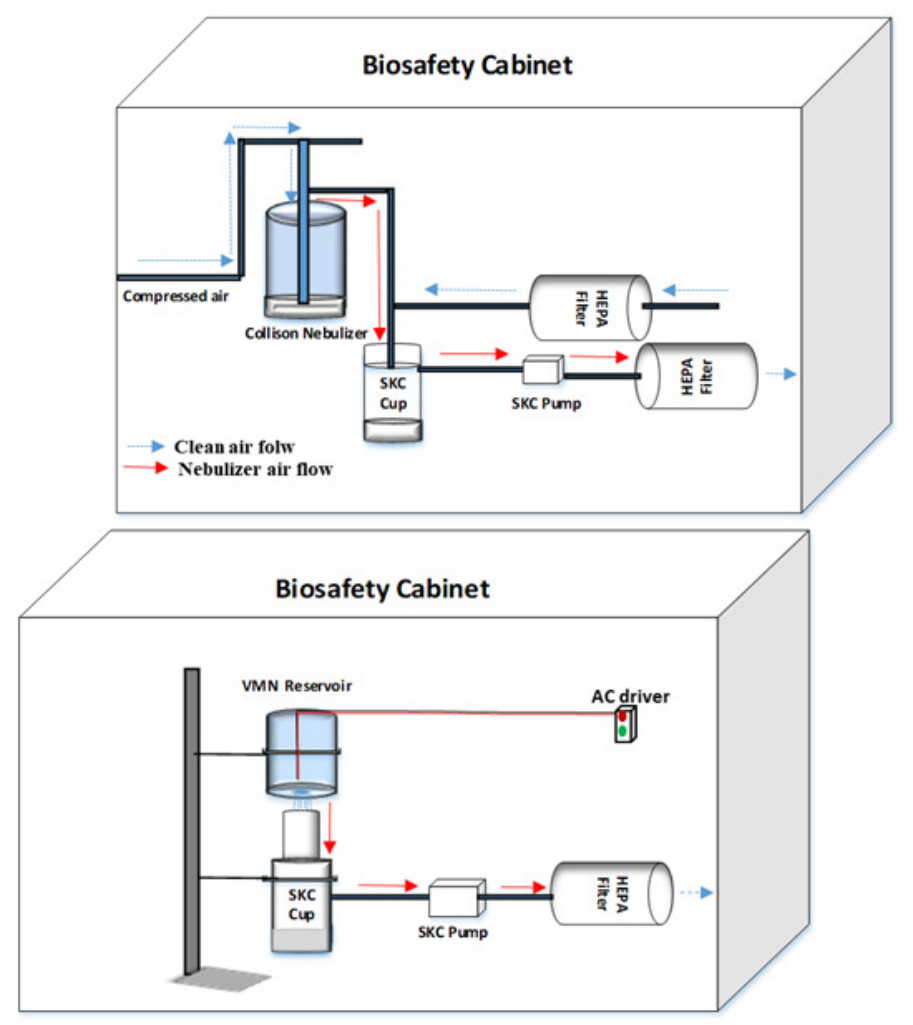

